\title{
23. ROCK MAGNETISM OF BASEMENT ROCKS, LEG 37
}

\author{
James M. Hall and Patrick J. C. Ryall,' Department of Geology, Dalhousie University, \\ Halifax, Nova Scotia, Canada
}

\section{INTRODUCTION}

Rock magnetism describes the magnetic properties of rocks seen as magnetic materials. In this report we will concentrate our attention on the nature and distribution of alteration of the Leg 37 basement rocks, and the effects of this alteration on the magnetic properties of the rocks. From fragmentary results, based on the study of material from dredge hauls and earlier DSDP legs, it is clear that the present magnetic state of the upper part of the layer depends strongly on its alteration history. In particular, the chemical interaction of seawater and basalt at close to sea bottom temperatures appears to be most important in the alteration of basalts. The long basement sections, of up to 583 meters, recovered during DSDP Leg 37 , for the first time allow us to examine the pattern of basalt alteration with depth and age. The results we describe are of interest beyond the magnetic state of the ocean crust. They bear too on the important question of heat loss from newly formed plate margins. If we see magnetic and other evidence for low temperature seawater alteration at depth in layer 2 , then the possibility of convection from the sea bottom to considerable depths in the layer is allowed, which in turn helps to explain the unexpectedly low measurements of conductive heat loss from spreading margins.

\section{EXPERIMENTAL METHOD}

The basic measurements here are of Curie temperature and saturation magnetization. These are obtained from the same experiment with a Curie balance. The balance consists of a $7.5 \mathrm{kG}$ electromagnet with Faraday pole pieces, a furnace designed to produce heating rates of up to $100^{\circ} \mathrm{C} / \mathrm{min}$, a Cahn $\mathrm{R}-100$ electrobalance, and a BBN $800 \mathrm{M}$ X-Y recorder. Repeated purging of the furnace with nitrogen before thermal cycling to $600^{\circ} \mathrm{C}$ of $10-20 \mathrm{mg}$ rock chips ensured that the effective oxygen fugacity was below that required to oxidize titanomagnetite grains.

Natural remanence intensity $\left(J_{[0]}\right)$, mean demagnetizing field (MDF), and initial susceptibility $(k)$ were obtained from measurements described in Hall and Ryall (Chapter 16, this volume).

The degree of titanomagnetite cation deficiency, $z$, was obtained from Curie point values as described in Ade-Hall et al., 1976b.

\footnotetext{
'Now at: School of Physics, Universiti Sains Malaysia, Minden, Pulau Pinang, Malaysia.
}

Titanomagnetite grain size and abundance were obtained for 100 selected samples using a Quantimet automatic image analyzing microscope.

Some of the rock magnetism interpretations depend critically on ore microscope observations made with a Zeiss Ultraphot microscope and reported in Opaque Mineralogy of Basement Rocks, Leg 37 (this volume).

\section{ALTERATION STATES OF MAGNETIC MINERALS}

We now recognize three general divisions among the observed alteration products states of basaltic titanomagnetites, corresponding to three different physical states under which alteration occurs. In basalts from the upper part of oceanic layer 2 low temperature, isothermal alteration is dominant with high temperature (initial cooling) and intermediate temperature zeolite metamorphic facies types of alteration only occurring rarely. The isothermal alteration of magnetite is part of the halmyrolitic alteration of the basalt as a whole, which takes place on the interaction of basalt and oxygenated seawater at temperatures of no more than a few tens of degrees centigrade (Seyfried et al., 1976).

Identification of the action of a particular alteration process requires a combination of magnetic tests and ore microscope observations. Anticipating a result described more fully later in this chapter and Hall and Fischer (Chapter 69, this volume), we see that isothermal alteration is, with rare exceptions, the only alteration process to have acted on the titanomagnetite of the Leg 37 basalts. The degree of titanomagnetite isothermal alteration is described in terms of the extent of titanomagnetite cation deficiency, ranging from 0.00 for unoxidized stoichiometric phases to 1.00 , the latter representing the complete replacement of $\mathrm{Fe}^{2+}$ by $\mathrm{Fe}^{3+}$ at a maximum state of alteration (Readman and O'Reilly, 1970). Cation deficiency describes the necessity for vacancies to appear in cation positions in the crystal lattice in order to maintain electroneutrality as $\mathrm{Fe}^{2+}$ is replaced by $\mathrm{Fe}^{3+}$. Ozima and Larson (1968) stated that cation deficient phases, or titanomaghemites, could not be restrained from phase splitting during thermal cycling, with gross change in magnetic properties, even where oxygen fugacity was very low. This property has since been extensively used to identify titanomaghemite from $J_{s-r}$ curves. However, Gromme and Mankinen (1976) have shown, by a combination of cell edge and Curie point measurements, that Ozima et al.'s (1974) conclusion applied only to highly cation deficient titanomagnetites, where $z$ ex- 
ceeds about 0.5 . For $0<z<0.5$, curves of the temperature change of saturation magnetization are reversible.

Examination of the curves for the thermal cycling of saturation magnetization for 425 Leg 37 basalts shows that only 23 are reversible (Table 1). It is important to see whether any of the 23 samples with reversible $J_{\text {S-T }}$ curves contain stoichiometric titanomagnetite. If this is the case, values for the ulvospinel content of the titanomagnetite can be obtained, and, this determined, values of $z$ determined for the collection as a whole. Our approach here has been that of careful ore microscope examination for signs of titanomagnetite cation deficiency in the samples having reversible curves. In fact, in all but one sample, 332B-8-1, 106-108 cm, all samples have indicators of a degree of cation deficiency, such as the limited development of volume change cracks (Ade-Hall et al., 1976a) and the presence of

TABLE 1

Degree of Titanomagnetite Stoichiometry in Samples Showing Reversible Saturation Moment Behavior on Thermal Cycling to $600^{\circ} \mathrm{C}$

\begin{tabular}{lccc}
\hline Sample & Number & $T_{c}{ }^{\mathrm{a}}$ & $z^{\mathrm{b}}$ \\
\hline Hole 332A & & \\
$12-1$ & $107-110(2)$ & 157 & 0.26 \\
$12-1$ & $108-111$ & 167 & 0.30 \\
$33-2$ & $61-64(2)$ & 167 & 0.30 \\
$33-2$ & $61-64(3)$ & 155 & 0.26 \\
$33-2$ & $61-64(4)$ & 150 & 0.23 \\
$33-2$ & $63-66$ & 153 & 0.24
\end{tabular}

Hole 332B

$\begin{array}{lcll}8-1 & 106-108 & 129 & 0.09 \\ 11-1 & 39-42(2) & 154 & 0.25 \\ 11-3 & 40-43(2) & 154 & 0.25 \\ 44-6 & 46-48(2) & 183 & 0.37 \\ 46-1 & 58-60(2) & 202 & 0.44 \\ 46-2 & 32-34(2) & 184 & 0.37 \\ 47-2 & 145-147 & 152 & 0.24 \\ 47-3 & 21-24(2) & 170 & 0.32\end{array}$

Hole 333A

$\begin{array}{lccc}3-1 & 129-131(2) & 170 & 0.32 \\ 6-1 & 16-18(2) & 155 & 0.26 \\ 9-4 & 98-100(2) & 135 & 0.15 \\ 10-2 & 106-109(2) & 164 & 0.30 \\ 10-2 & 112-115(2) & 165 & 0.30\end{array}$

Site 334

$\begin{array}{llll}16-2 & 109-112(2) & 206 & 0.45\end{array}$

Site 335

$\begin{array}{llll}14-4 & 130-136(\mathrm{~T}) & 150 & 0.23 \\ 14-4 & 130-143(\mathrm{RN}) & 182 & 0.36\end{array}$

${ }^{a}$ Curie Temperature

$\mathrm{b}_{z}$ is the proportion of $\mathrm{Fe}^{2+}$ oxidized to $\mathrm{Fe}^{3+}$.

$x$ in $x \mathrm{Fe}_{2} \mathrm{TiO}_{4}(1-x) \mathrm{Fe}_{3} \mathrm{O}_{4}$ is assumed to be 0.64 , see text for explanation. minor amounts of secondary phases. However, the degree of development of indicators of cation deficiency clearly decreases with decreasing Curie temperature in most units from which there are several samples with reversible curves. From the single sample without cation deficiency features, plus the trend in other groups of samples, it seems that cation deficiency features would generally be absent at a Curie temperature of about $120^{\circ} \mathrm{C}$. The corresponding ulvospinel content of a phase with a Curie temperature of $120^{\circ} \mathrm{C}$ is $x=0.64$ in the solid solution formula $x \mathrm{Fe}_{2} \mathrm{TiO}_{4}(1-x) \mathrm{Fe}_{3} \mathrm{O}_{4}$ (Readman and O'Reilly, 1972). It is notable that this value is close to the values reported for Nazca plate basalts (Ade-Hall et al., 1976b), for basalts from the Median Valley of the Mid-Atlantic Ridge (Schaeffer and Schwarz, 1970), and for subaerial basalts containing homogeneous titanomagnetite.

If a value of $x=0.64$ is taken as a first approximation to the titanomagnetite composition of the Leg 37 basalts as a whole, then values of cation deficiencies can be assigned throughout, and the question of the dividing line between samples showing reversible and irreversible thermal behavior is examined further. A set of $J_{\mathrm{S} \text {. T }}$ curves for intervals of $\sim 0.1$ in $z$ (assuming $x=$ 0.64 ) from $z \cong 0.1$ to $z \cong 0.9$ is shown in Figure 1. Note the reversibility $(R)$ of the first four curves and the relatively rapid increase in $z$ with rising Curie temperature. The last four curves show clear irreversible (IR) behavior, with $z$ increasing relatively slowly with rising Curie temperature. Curves five and six in Figure 1 (for Samples 332B-2-1, 24-27 cm and 335-8, 40-42 cm) show different types of slightly irreversible (SIR) behavior. It seems justifiable to set up a third category of $J_{\text {S-T }}$ curves, with properties corresponding to these latter two samples. Analysis of our data for the distribution of the three classes shows that a fairly small range in Curie temperatures marks the appearance or disappearance of each type of curve (Figure 2). Thus, with one exception, the abundance of $\mathrm{R}$ type curves drops from $100 \%$ to $0 \%$ between $155^{\circ} \mathrm{C}$ and $195^{\circ} \mathrm{C}$. Likewise SIR curves extend from $165^{\circ} \mathrm{C}$ to $235^{\circ} \mathrm{C}$ and IR curves, with four unexplained low temperature exceptions, rise from $0 \%$ to $100 \%$ in the $195^{\circ} \mathrm{C}$ to $255^{\circ} \mathrm{C}$ interval. A simple explanation for the range in onset or disappearance of each type of behavior is in the occurrence of a range of $x$ values. If the onset of IR behavior (for example) is a function only of $x$, then the range of onset temperatures is a measure of the range in $x$, in this case amounting to \pm 0.02 for a mean value of $x=0.64$. Similarly based estimates for R and SIR behavior yield slightly smaller apparent ranges in $x$. In practice, these temperature ranges may have less simple explanations, perhaps involving the variation in onset temperature with $z$, the influence of varying amount and kind of impurity elements, or heterogeneity of oxidation.

\section{DISTRIBUTION OF DEGREE OF TITANOMAGNETITE CATION DEFICIENCY}

If a value of $x=0.64 \pm 0.02$ is taken as representative of the Leg 37 basalts, values of the degree of titanomagnetite cation deficiency, $z$, can be assigned to 

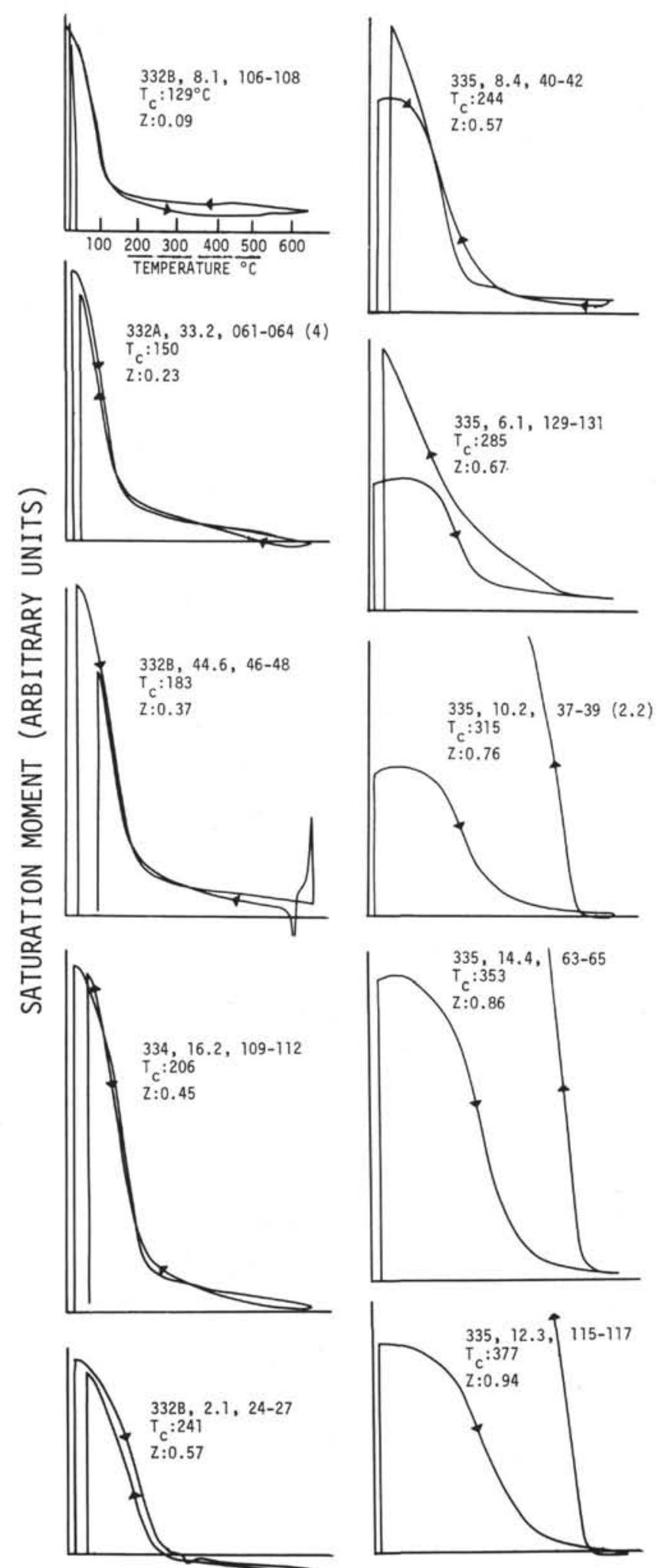

Figure 1. Temperature dependence of saturation magnetization for a set of samples containing titanomagnetite at intervals of cation deficiency from $z=0.09$ to $z=0.94$.

each sample and the important features of the overall distribution of cation deficiency investigated, as well as the differences in distributions for different rock types

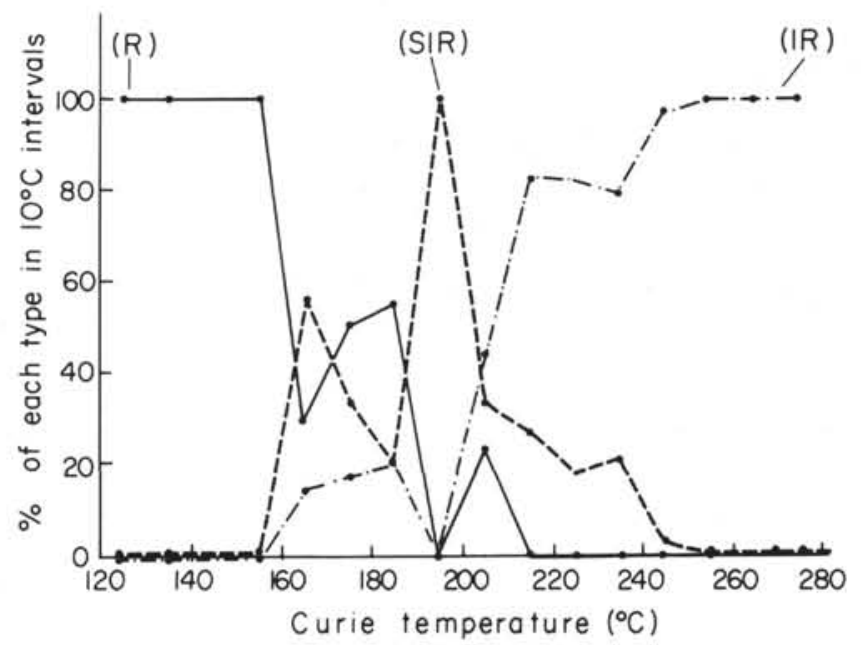

Figure 2. Onset and disappearance of reversible, slightly irreversible, and irreversible behavior during the thermal cycling of saturation magnetization.

and age groups. Values of $z$ are shown adjacent to the listing of Curie temperatures in Table 1. The uncertainty in $z$, corresponding to the uncertainty in $x$ of \pm 0.02 , decreases rapidly with the value of $z$ from $\pm 12 \%$ for a Curie temperature of $150^{\circ} \mathrm{C}$ to $\pm 2 \%$ for a Curie temperature of $400^{\circ} \mathrm{C}$.

Figure 3 shows the distribution of $z$ for all the Leg 37 basalts. Note the relatively uncommon nature of low $z$ samples and the peak in the distribution between $z=$ 0.6 and $z=0.8$. Generally then, the Leg 37 basalts contain highly cation deficient titanomagnetite, a feature which is likely to influence strongly their magnetic properties. O'Reilly and Banerjee (1966) have shown theoretically that, for titanomagnetites where $x$ exceeds 0.6 , a high degree of cation deficiency could lead to selfreversal of NRM. According to their model, as $x$ increases from 0.62 to 0.66 , the appropriate range of compositions for the Leg 37 basalts, the value of $z$ at which self-reversal is expected to occur falls from 0.96 to 0.92 . We note from Figure 3 that $6.6 \%$ (27) of the Leg 37 basalts have $z>0.90$. If some of these samples had selfreversed, then their polarity would oppose that of less oxidized samples from the same lithological unit. In no case is there such polarity opposition. Therefore, either the model of O'Reilly and Banerjee does not match the

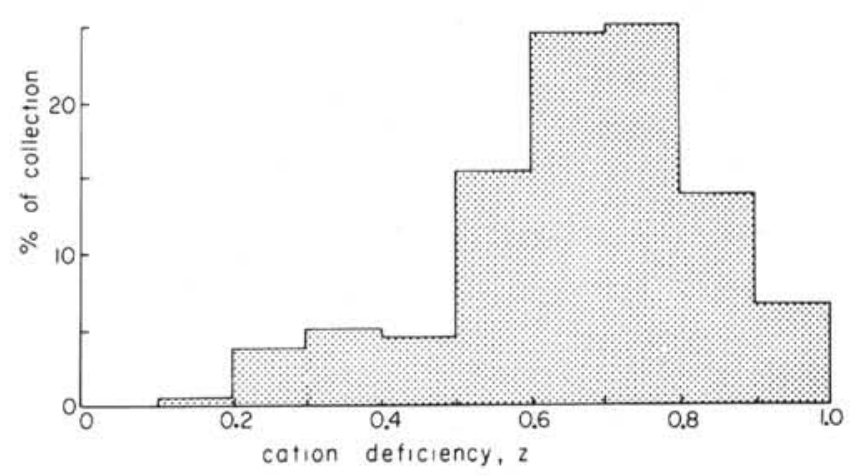

Figure 3. Overall distribution of titanomagnetite cation deficiency for the Leg 37 basalts. 
natural process of cation deficiency formation, or it is just possible that none of the samples has a combination of $x$ and $z$ within the self-reversal region.

Next we consider the variation of degree of titanomagnetite cation deficiency with site age, since some dependence of $z$ on age might be anticipated (Figure 4). At the two older holes values of $z$ of less than 0.7 are relatively uncommon. Beyond this general distinction, however, the patterns of distributions and average values are not simply related. Thus, at the three holes of identical relatively young age (332A, 332B, 333A) average cation deficiency varies widely, with $332 \mathrm{~A}$ and $333 \mathrm{~A}$ indistinguishable and 332B with a distinctly higher average value (Table 2 ). Thus, the contrast in paleomagnetic stratigraphy between Holes $332 \mathrm{~A}$ and 332B, only 107 meters apart, is also apparent in their relative degrees of alteration. In fact, the relatively high degree of titanomagnetite cation deficiency at Hole $332 \mathrm{~B}$ is indistinguishable from the average value for the Site 334 basalts, which are a factor of three older, and is only slightly less than the value for the oldest site, Site 335.
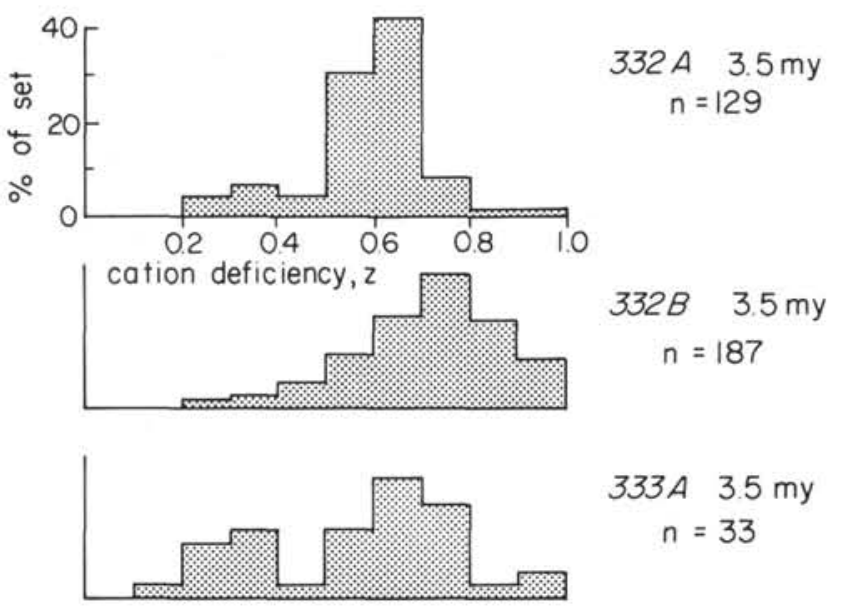

$333 \mathrm{~A} 3.5 \mathrm{my}$ $n=33$

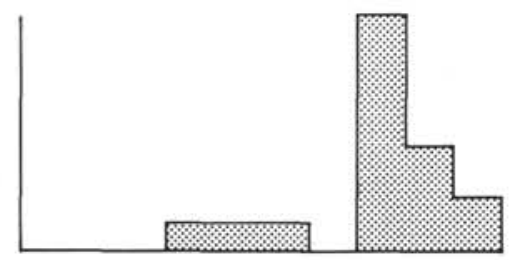

$$
3348.9 \mathrm{my}
$$$$
n=18
$$

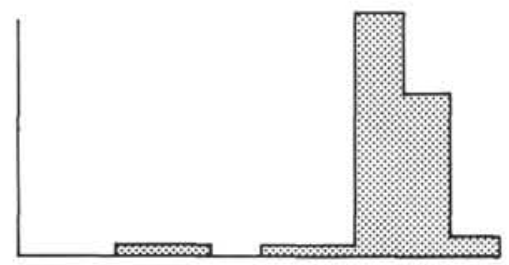

$33516.5 \mathrm{my}$

$n=43$

Figure 4. Distributions of titanomagnetite cation deficiency for basalts from each Leg 37 hole.

These results support the contention of Irving et al. (1970) and Johnson and Atwater (in press) that a major part of the alteration of the upper part of layer 2 takes place rather shortly after eruption and is apparent by
TABLE 2

Average Titanomagnetite Cation Deficiency, $\bar{z}$, for Basalts from Leg 37 Holes

\begin{tabular}{lccc}
\hline Hole & Age (m.y.) & $\begin{array}{c}\text { Number of } \\
\text { Values }\end{array}$ & $\begin{array}{c}\text { Average Value } \\
\bar{z} \pm \text { S.D. of Average }\end{array}$ \\
\hline 332A & 3.5 & 129 & $0.58 \pm 0.01$ \\
$332 \mathrm{~B}$ & 3.5 & 187 & $0.70 \pm 0.01$ \\
$333 \mathrm{~A}$ & 3.5 & 35 & $0.56 \pm 0.01$ \\
334 & 8.9 & 18 & $0.74 \pm 0.04$ \\
335 & 16.5 & 43 & $0.76 \pm 0.02$ \\
\hline
\end{tabular}

the time that the basalts are transported to the walls of a Median Valley.

It has been suggested by Ozima et al. (1974) that cation deficiency, if controlled solely by diffusion of seawater from the upper surface of layer 2 , would extend only to a depth of a few tens of meters in crust older than $5 \times 10^{7} \mathrm{yr}$. It is clear from the high average cation deficiencies for all the Leg 37 holes that the effect of the process extends at least to 582 meters in 3.5 m.y., implying a very much faster rate of penetration than is predicted by Ozima et al. In fact, as Ozima et al. suggest, solid diffusion is clearly the slowest of several processes involved in bringing oxygenated seawater into contact with titanomagnetite grains. In order to investigate the progress of low temperature oxidation through the upper part of layer 2 , we first present depth profiles of average cation deficiency for 50 meter intervals (Figure 5) followed by profiles of Curie temperature with depth (Figure 6a-e). The purpose of the two types of presentation is that very different wavelengths in alteration patterns may be resolved. The 50 meter average cation deficiency profiles show no simple pattern of long wavelength variation in $z$, neither is there any suggestion of a common pattern of variation. At three holes $(332 \mathrm{~A}, 332 \mathrm{~B}, 335)$ there is a decrease in $z$ in the topmost 100 meters. However, no such decrease occurs in Hole 333A. In two deep holes, $333 \mathrm{~A}$ and 332B, low $z$ values are common at the bottom of the holes although the depths differ by a factor of two. However, this arrangement does not occur in Hole $332 \mathrm{~A}$. It turns out that $z$ is related not to the depth but rather to the physical construction of the lithological units through upper layer 2. Thus, rather massive basalts are characterized by low $z$ values in the vicinity of 200 meters subbasement in Hole 332B and again at the bottom of Holes 332B and 333A, whereas pillow sequences, characterized by high $z$, occur in the vicinity of 300 meters subbasement in Hole 332B and comprise all the recovered basalts at Sites 334 and 335. This relationship between the progress of halmyrolytic alteration and the structure of lithological units is also apparent in Nazca plate basalts (Ade-Hall et al., 1976b).

Curie temperature profiles (Figure 6) show details of the distribution of $z$, usually on a scale of a few meters. The isolated nature of low $z$ samples in the pillow sequences of Sites 334 and 335 is striking. At Site 335 , for example, a single $\sim 10 \mathrm{~cm}$ length of fresh looking gray basalt containing low $z$ titanomagnetite occurs within a 108-meter sequence of brown-stained basalt with high $z$ titanomagnetite. The sharp spikes of 

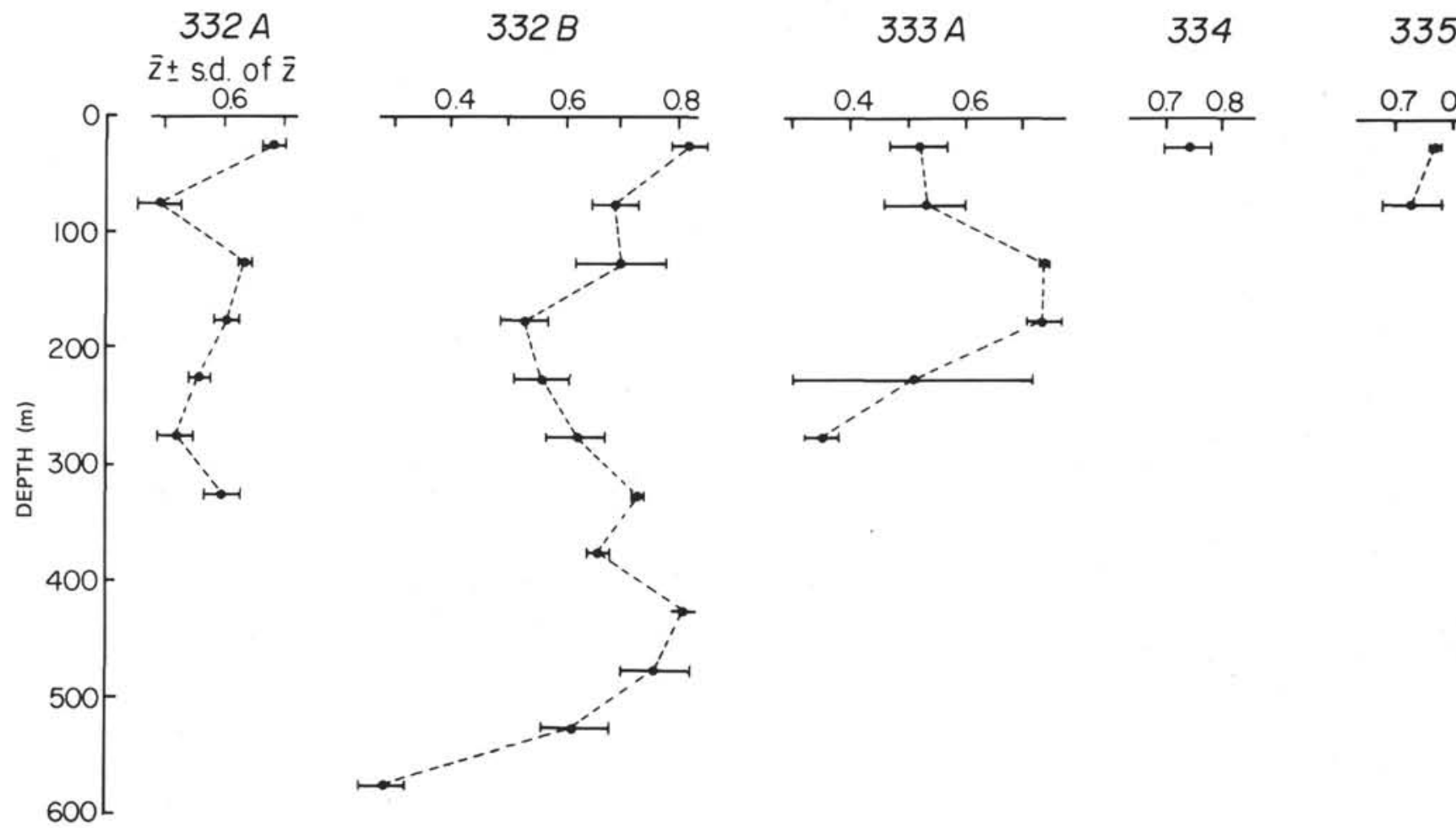

Figure 5. Average titanomagnetite cation deficiency over 50 meters depth intervals for the basalts from each Leg 37 Hole.

remaining little-oxidized material in the Site 334 and 335 pillow sequences, and their apparent complete absence from the Site 332B pillow sequences, bear witness to the efficacy of rapid seawater penetration into this type of material, presumably via pillow boundaries and fractures. Rather more extensive zones of low $z$ basalts occur in massive basalts, particularly at the bottom of Holes 332B and 333A. Here seawater penetration has been more restricted than in pillow sequences.

The preferential alteration of pillow sequences can easily be explained providing the penetration of seawater along interpillow zones is very fast compared with its diffusion into basalts. Consider two representative 10-meter-thick lithologic units in layer 2, in one case consisting of massive basalt and the other of interlocking pillows averaging 1 meter in diameter. In the time required for seawater to diffuse 0.5 meter into basalt, all the pillows will be altered while the central 9 meters of the massive unit will still be unaltered.

\section{HIGH CURIE POINT SAMPLES}

For a composition of $x=0.64$ in $x \mathrm{Fe}_{2} \mathrm{TiO}_{4}(1-$ $x) \mathrm{Fe}_{3} \mathrm{O}_{4}$ a complete cation deficiency, where $z=1.00$, has a corresponding Curie point of $470^{\circ} \mathrm{C}$, (Readman and O'Reilly, 1972). Thus any sample having a higher Curie point than $470^{\circ} \mathrm{C}$ must have a different type of magnetic constituent. In fact, 14 samples, 10 basalts and 4 ultramafic rocks, do have Curie points in excess of $470^{\circ} \mathrm{C}$.

The high Curie point basalt samples appear to fall into two groups. Three samples (332B-33-2, $85-88 \mathrm{~cm}$ [1]; 332B-44-5, 61-63 cm [1]; and 333A-6-2, 92-94 cm
[2]) show either overall red or brown staining or reddening of olivine phenocrysts. This suggests that high temperature initial cooling oxidation of the samples has led to the phase splitting of the original titanomagnetites to magnetite (s.s.) and ilmenite, with the magnetite responsible for the high Curie points. The oxide phase of all three samples is very fine grained, and while clearly gray in color instead of the brown of titanomagnetite or its cation deficient derivatives, is too finely divided for internal features, such as the products of phase splitting, to be resolved. The remaining seven high Curie point basalt samples (332B-3-2, 112-115 cm; $332 \mathrm{~B}-33-2,27-30 \mathrm{~cm}$ [2]; 332B-37-1, 73-75 cm; 332B-37$1,126-128 \mathrm{~cm} ; 332 \mathrm{~B}-33-2,27-30 \mathrm{~cm}$ [2]; 332B-37-1, 73$75 \mathrm{~cm} ; 332 \mathrm{~B}-37-1,126-128 \mathrm{~cm} ; 332 \mathrm{~B}-37-2,102-105 \mathrm{~cm}$; 332B-43-1, 105-107 cm [2]; and 332B-45-1, 104-106 cm [2]) are with one exception from the lowermost 100 meters of Hole 332B. While a degree of orange staining of these samples, indicating the migration of iron, is apparent on microscopic examination, the oxide phase is a brown or gray-brown cation deficient titanomagnetite. The explanation for the high Curie points for this group lies in phase splitting of unstable oxides during laboratory thermal cycling. This is apparent from examination of the $J_{\text {S-T. }}$ curves, which always show evidence of two Curie points, the lower less well marked and probably representing the oxide phase in its natural state and the higher representing nearly pure magnetite produced during the heating part of the thermal cycle. Thus, even with a Curie balance capable of a heating rate in excess of $100^{\circ} \mathrm{C} / \mathrm{min}$, it is still impossible to restrain phase splitting in a small number of samples before the Curie point of the naturally occurring iron oxide phase can clearly be resolved. 

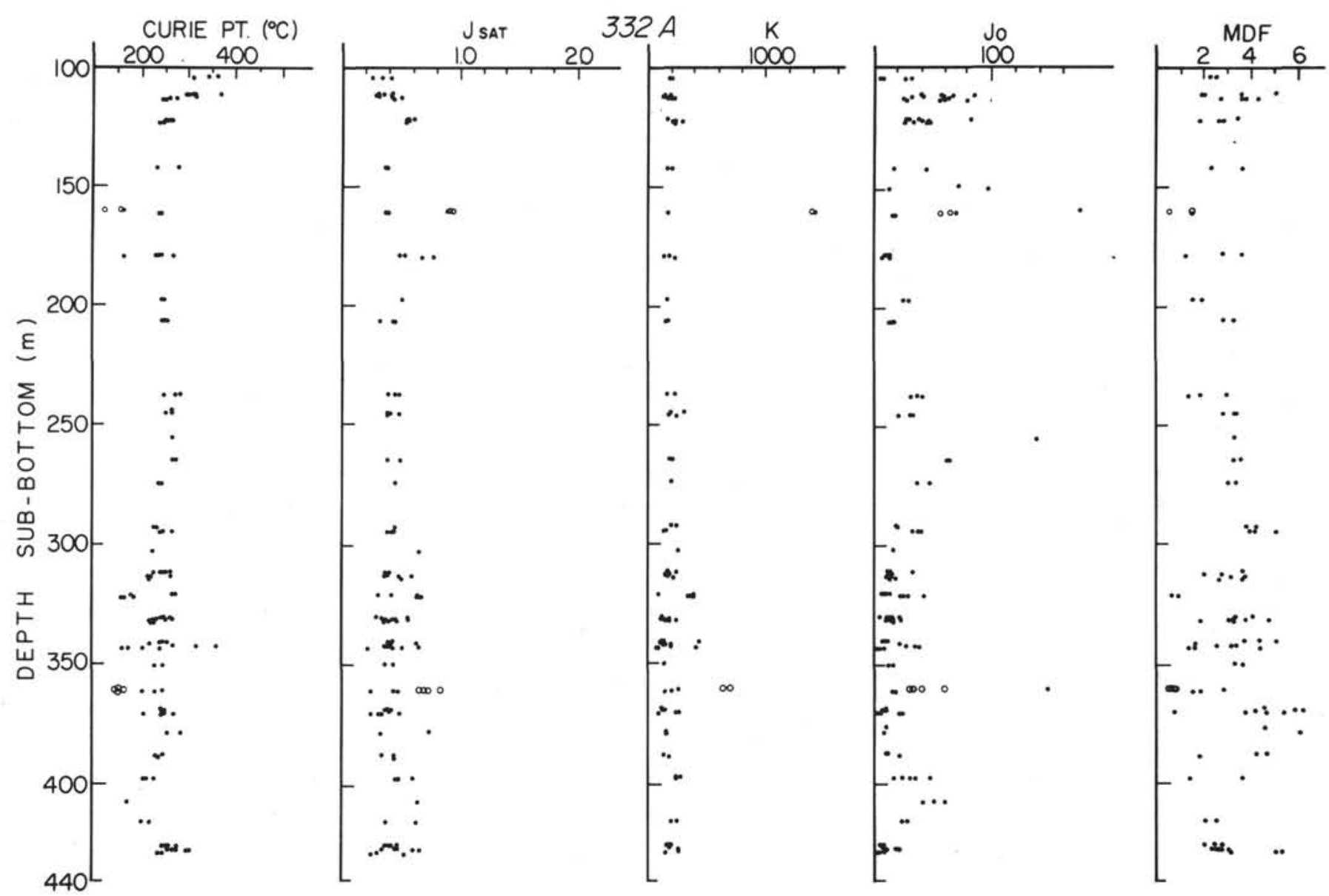

Figure 6. Distribution with depth of basement rock magnetic properties at the Leg 37 holes: $332 \mathrm{~A} ; 332 \mathrm{~B} ; 333 \mathrm{~A} ; 334 ; 335$.

(Lines join double Curie points. Open circles are for samples showing reversible thermal cycling of saturation magnetization.)

All four samples from the brecciated plutonic melange of Site 334 having detectable Curie points yield values in excess of $500^{\circ} \mathrm{C}$. One sample, 334-23-1, 127 $130 \mathrm{~cm}[2]$, contains rare euhedral primary magnetite grains, presumably with titanium or other impurity elements present in a relatively small concentration consistent with the $527^{\circ} \mathrm{C}$ Curie point. The three remaining samples (334-22-2, 61-63 cm [2]; 334-24-4, 95-98 cm [2]; and 334-26-1, 20-22 cm [2]) have Curie points indistinguishable from that of pure magnetite. Microscopic examination of these samples shows that their oxide phase consists of chains, patches, and isolated grains of magnetite derived from the serpentinization of olivine.

\section{UNDERSTANDING THE PRESENT MAGNETIC STATE OF UPPER LAYER 2}

Here we are concerned with the magnetic evolution of upper layer 2 as it is transported away from the spreading center at which it is formed. This is a question of fundamental importance in plate tectonics as the magnetic state of the layer determines the magnetic anomalies observed above it, these in turn producing isochrons and structural history indicators for the oceanic parts of plates. It is already quite clear that low temperature interaction of basalt with seawater has the most drastic effect on the magnetic properties of the basalts of upper layer 2 (Irving et al., 1970; Ade-Hall et al., 1976b). With the good recovery of layer 2 basalts during DSDP Leg 37, we have the first opportunity to delineate exactly the effects of this alteration process and to separate it as a variable from other influences on magnetic state such as original magnetizing field strength, titanomagnetite abundance, and titanomagnetite grain size and shape. Titanomagnetite composition, in terms of the ratio of magnetite and ulvospinel molecules, is also a potential variable, but the results described in the previous sections, and from other studies, indicate that for submarine basalts this may be taken as constant to a first approximation.

The results described below are for a preliminary statistical analysis of the rock magnetic data. They are in the form of the interpretation of sets of scattergrams obtained using a standard SPSS (Statistical Package for the Social Sciences) program package. It is clear from many of these scattergrams that different laws often describe the data in different parts of the data field. Extension of this statistical analysis, to be reported elsewhere, will describe quantitatively the behavior of data in the different part of fields. In the sections that follow, we describe sets of scattergrams, first for the Leg 37 basalts as a whole and then for the basalts from 


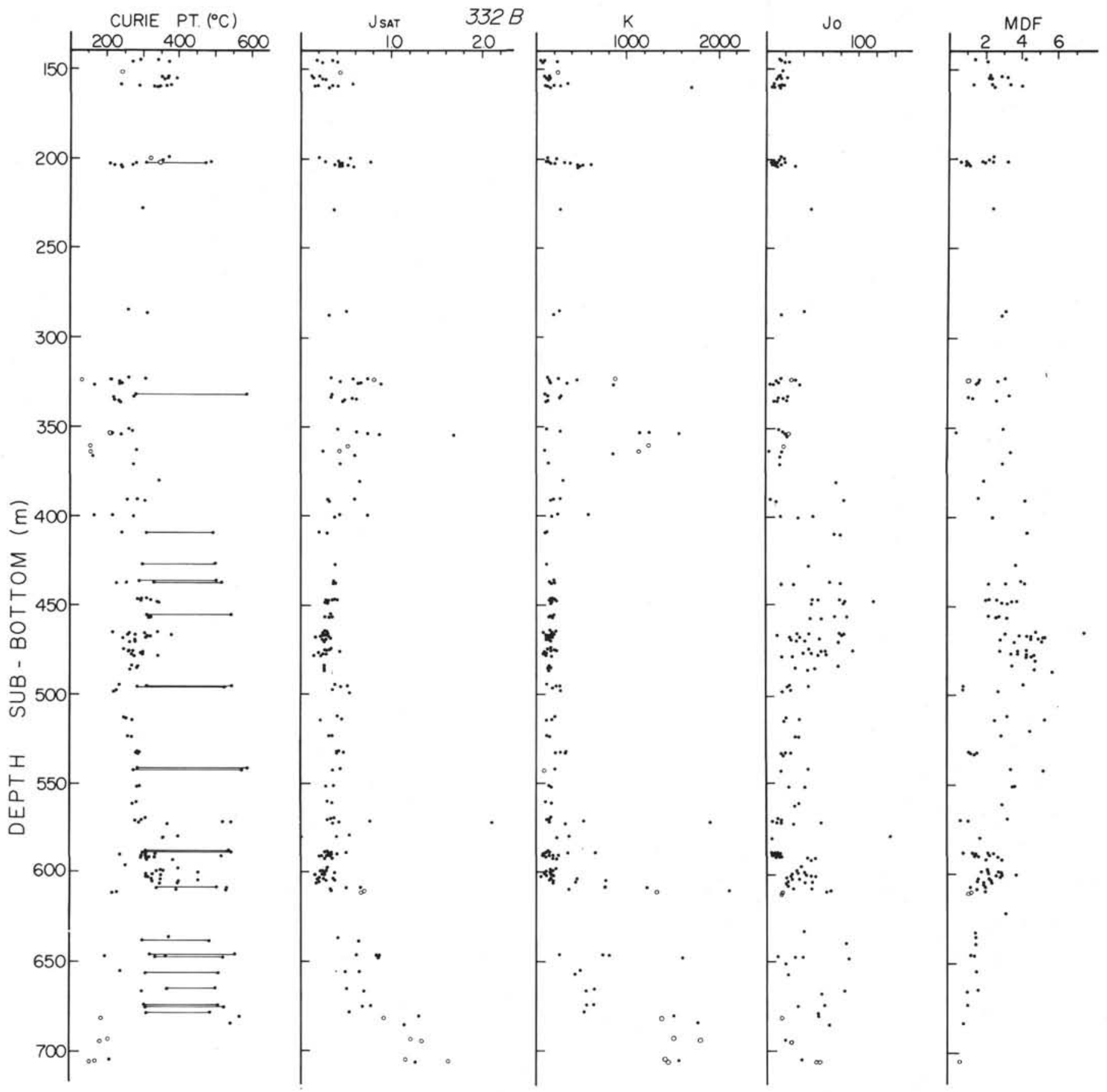

Figure 6. (Continued).

each Leg 37 hole. Linear trends will be identified, with visual estimates of the average change in property value over the extent of the trend, and a physical interpretation of each trend attempted.

\section{NRM Intensity and Curie Point}

(In this and the other scattergrams involving Curie point, the Curie point axis is also the axis of increasing low temperature alteration.)

For the Leg 37 basalts as a whole NRM intensity does not relate in any obvious way to Curie point. However, at several holes $(332 \mathrm{~A}, 333 \mathrm{~A}, 334$, and

perhaps 335) the distributions may be seen as comprising two trends, a rapid decrease of NRM with rising Curie point for different ranges of relatively low Curie points followed either or both by a region where NRM intensity is independent of Curie point or increases with Curie point. The magnitude of the initial decrease ranges from a factor of 3 to a factor of 20 .

Trends in these scattergrams are generally relatively poorly developed. This probably is explained by the significant dependence of NRM intensity on a number of factors, including intensity of original magnetizing field and titanomagnetite grain size and content, as well 


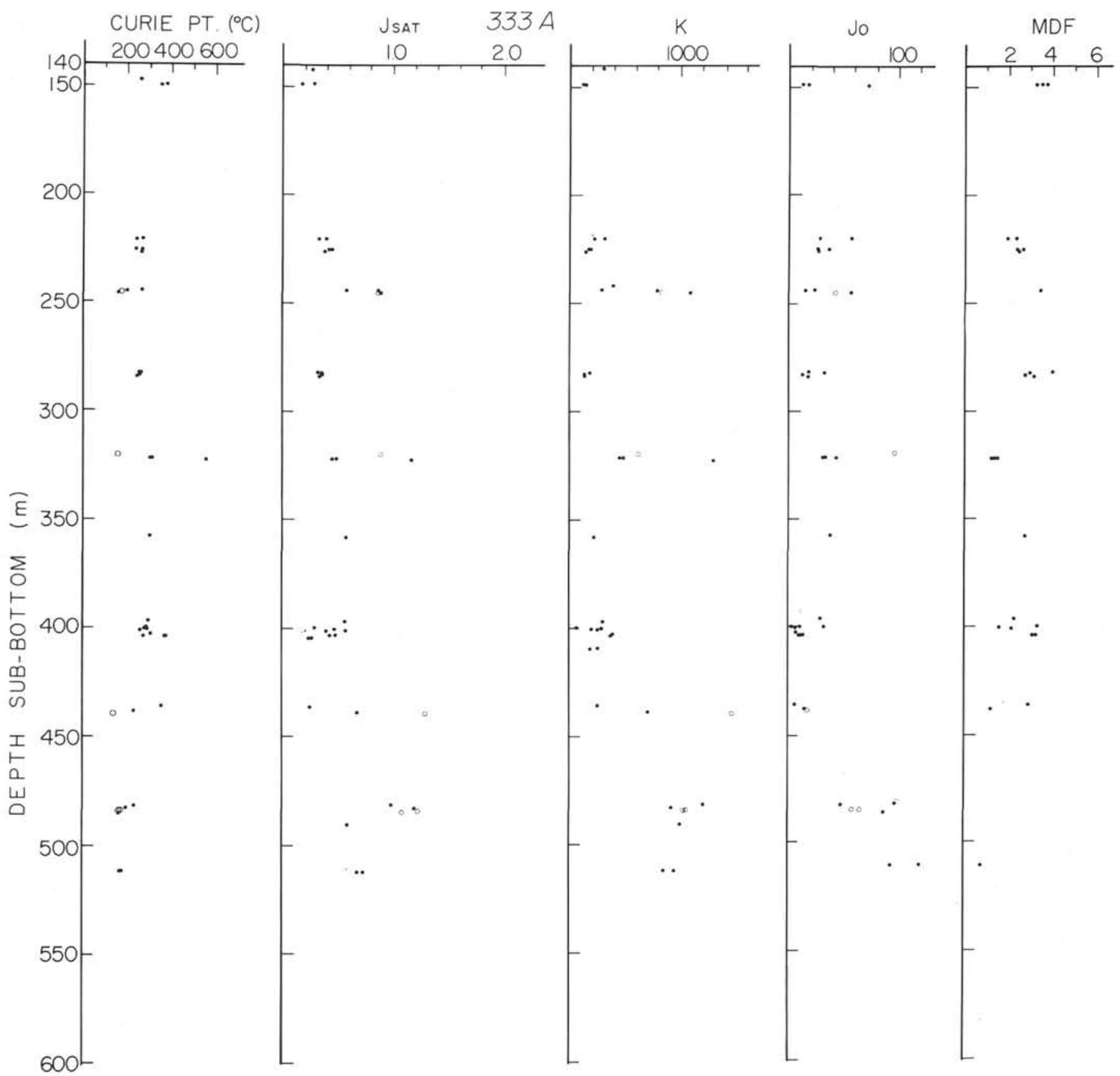

Figure 6. (Continued).

as titanomagnetite cation deficiency. We intend to try to separate these factors by further statistical analysis in order to evaluate their relative importance.

\section{Susceptibility and Curie Point}

Part or all of three linear trends are seen in all the scattergrams for these parameters (Figure 7). Susceptibility decreases very rapidly with increasing Curie point from $127^{\circ}$ to $220^{\circ}$ to $270^{\circ} \mathrm{C}$, with the magnitude of the decrease ranging from a factor of 3 to an order of magnitude and averaging at a factor of 6 . From $220^{\circ}$ to $250^{\circ} \mathrm{C}$ to about $400^{\circ} \mathrm{C}$ susceptibility varies little if any with Curie point, maintaining relatively low values throughout the interval. At above $500^{\circ} \mathrm{C}$ susceptibility rises rapidly with Curie point, with an order of magnitude increase to a Curie point of $580^{\circ} \mathrm{C}$. The initial decrease in susceptibility with rising Curie point is most readily explained as the combined effects of diminished intrinsic susceptibility and increased grain subdivision with cation deficiency increasing from zero to $0.50-0.65$. The median region where susceptibility changes little, if any, with increasing Curie point does not have an obvious explanation. However, the rapid increase of susceptibilities at high Curie points is readily explained in terms of the presence of pure magnetite produced from the phase splitting of cation deficient titanomagnetites. 


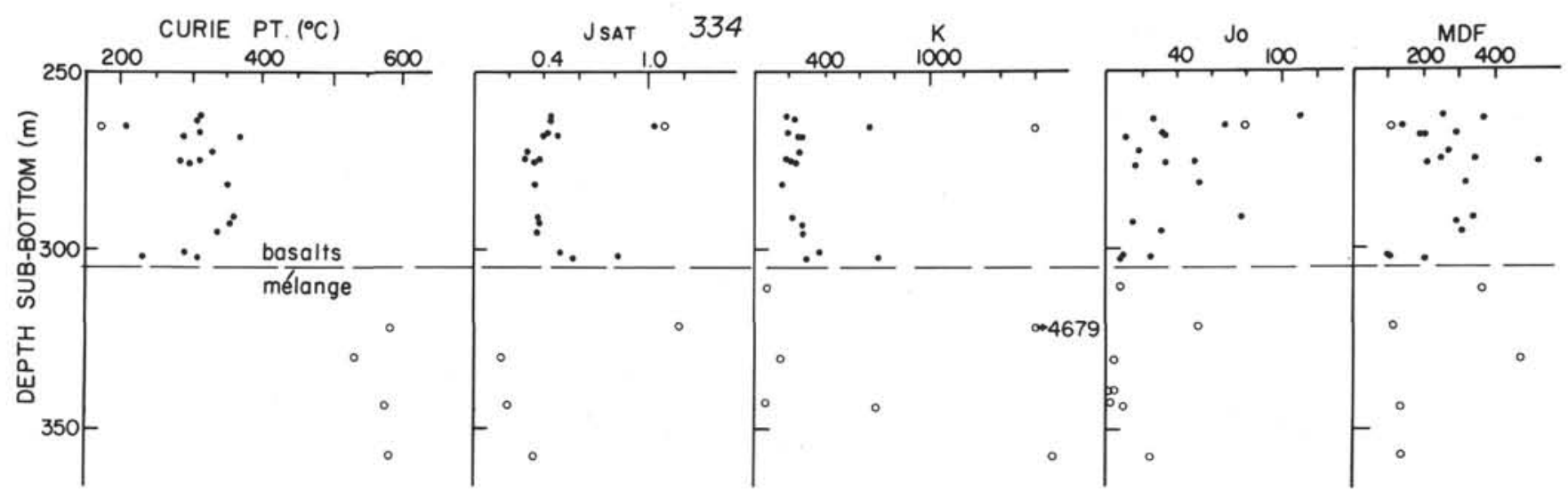

Figure 6. (Continued).
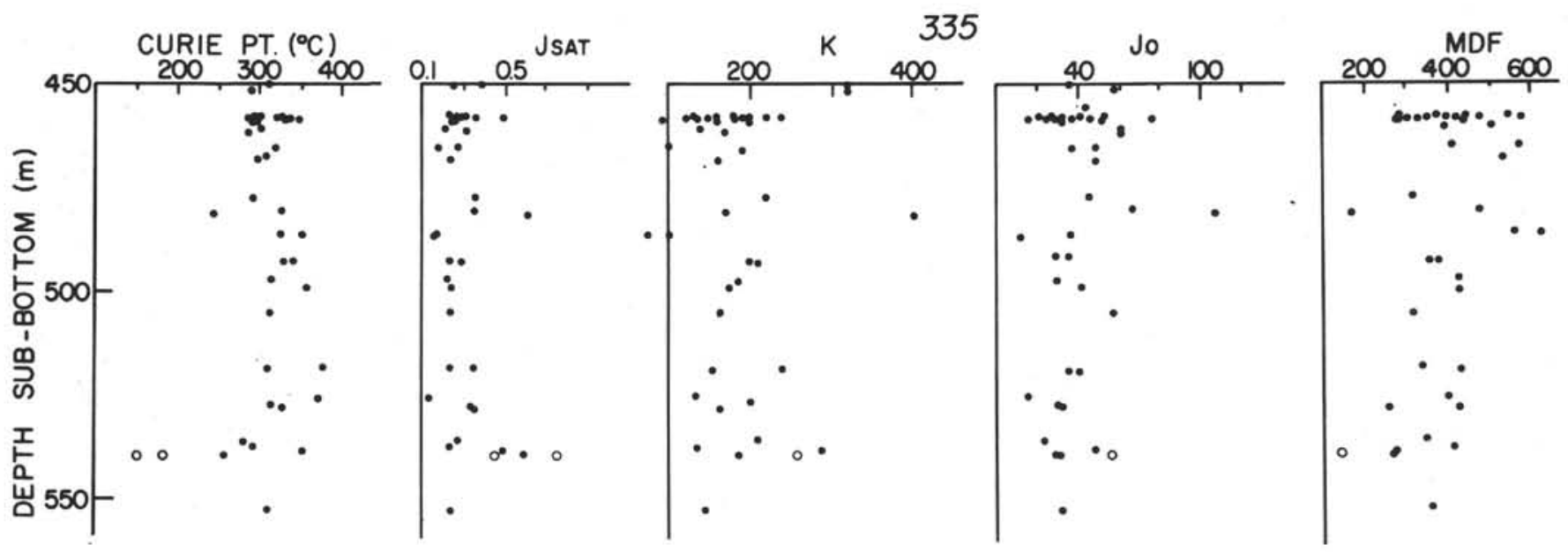

Figure 6. (Continued).

\section{$Q$ Ratio and Curie Point}

All the scattergrams show a similar relationship between these parameters (Figure 8). The relationship is one of a bilaterally symmetrical distribution of $Q$ with respect to Curie point, with values of $Q$ in excess of 100 only occurring for a Curie point interval from $240^{\circ} \mathrm{C}$ to $330^{\circ} \mathrm{C}$, or equivalent cation deficiencies of 0.6 to 0.8 . The form of the distribution is the result of different dependencies of NRM and susceptibility on Curie point. This is an important result as it implies that fairly highly oxidized basalts are the best material in terms of the ratio of remanent to induced magnetization for magnetic anomaly production. Near stoichiometric or phase-split oxides are less suitable in this regard. For the Leg 37 basalts, at least, the 0.6 to 0.8 cation deficiency interval also contains the most samples. It is ironic, then, that while conditions are optimum in the Leg 37 basalts for clear magnetic anomaly production, there are major difficulties in accounting for the linear anomaly pattern over the sites of the deepest holes into layer 2 !

\section{Mean Demagnetizing Field (MDF) and Curie Point}

The stability of NRM, described by MDF, shows two types of behavior, a broad increase of MDF with Curie point to a $400^{\circ} \mathrm{C}$ followed by a zone where MDF is independent of Curie point. Average MDF increases from a few tens of oersteds for Curie points close to $120^{\circ} \mathrm{C}$ to about 450 oe for Curie points close to $400^{\circ} \mathrm{C}$. Above $400^{\circ} \mathrm{C}$, MDF varies irregularly between 100 and 200 oe. Clearly, increase in titanomagnetite cation deficiency results in increasingly stable paleomagnetic material, although CRM may perturb the NRM of some highly oxidized samples (Gromme and Mankinen, 1976). However, while it is tempting to assume that increased cation deficiency is physically responsible for increased stability, we should bear in mind that samples with highly cation deficient titanomagnetite are often very fine grained samples, and fine grained, single domain, or pseudo-single domain magnetite grain size is also a candidate to produce high NRM stability. Further analysis of the data, in an attempt to separate the relative effects of these two variables, is clearly called for here.

\section{Saturation Magnetization, $J_{s}$, and Curie Point}

As a consequence of the ubiquitous and relatively simple relationship between $J_{s}$ and susceptibility, described below, both $J_{s}$ and susceptibility relate to Curie point in a very similar fashion. Thus, $J_{s}$ decreases rapidly with increasing Curie point to $220^{\circ}-275^{\circ} \mathrm{C}$, a decrease of a factor of 2 to 3 being representative. This must be due to the intrinsic decrease of $J_{s}$ with cation 


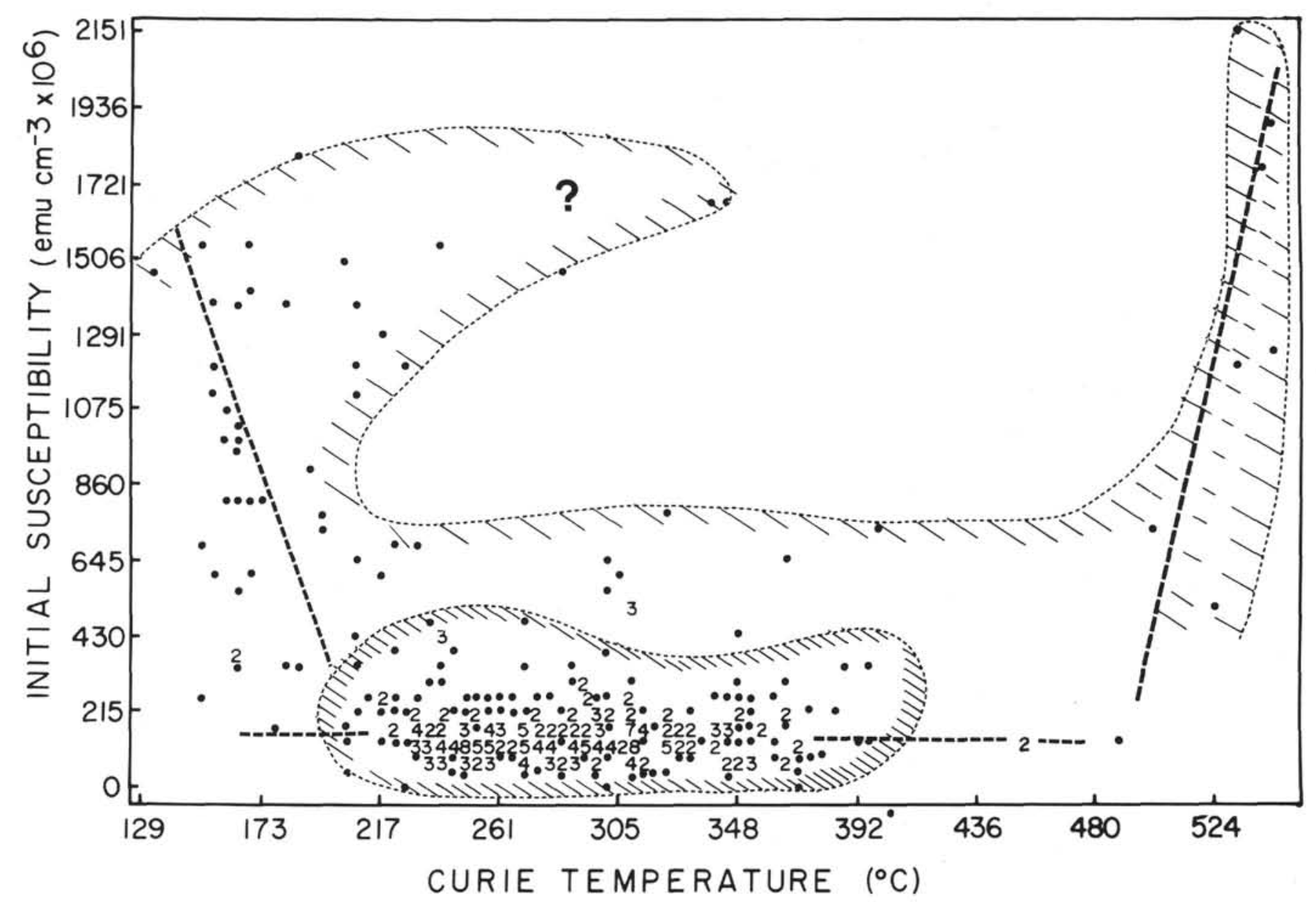

Figure 7. Relationship between initial susceptibility and Curie temperature for the Leg 37 basalts.

deficiency to values of $0.50-0.65$. A zone with little dependence of $J_{s}$ on Curie point separates the initial rapid fall from a rapid rise in $J_{s}$ at high Curie points. The latter must be due to the production, by phase splitting, of increasing amounts of high $J_{s}$, near-pure, or pure magnetite. A factor of four increase in $J_{s}$ from $450^{\circ} \mathrm{C}$ to $580^{\circ} \mathrm{C}$ occurs in this interval.

\section{Susceptibility, $k$, and NRM Intensity, $J_{o}$}

There is no single pattern for the relationship between these parameters. In two holes (332A, 332B) two linear branches are discernible, one terminating at high $k$ and moderately high $J_{o}$ values and the other at high $J_{o}$ and low $k$ values. The former contains low Curie point samples at its extremity, the latter no single type of sample. Since the low Curie point sample branches for Holes 332A and 332B do not coincide, the scattergram for all the Leg 37 basalts shows no clear trends.

\section{Saturation Magnetization, $J_{s}$, and Susceptibility, $k$}

These parameters are strongly directly correlated throughout (Figure 9). In some holes (332A, 332B, 335) taken individually, there are suggestions of gradient breaks but these are not apparent when the data from all holes are plotted together. This simple relationship indicates that for the titanomagnetite grain size range of the Leg 37 basalts susceptibility depends only on the volume and degree of cation deficiency of the titanomagnetite of a sample.

NRM Intensity, $J_{o}$, and Saturation Magnetization, $J_{S}$

The distributions for different holes are all complex, with two branches often being apparent. One leads to high $J_{s}$ and moderate $J_{o}$ values and other to high $J_{o}$ and low $J_{s}$ values. No explanation is offered for these trends.

NRM Intensity, $J_{o}$, and the Ratio of Titanomagnetite Content to Grain Size

Very broad linear increase of $J_{o}$ with the ratio characterizes this relationship, with $J_{o}$ increasing on the average by a factor of 4 for a 25 -fold increase in the ratio. This relationship and the following one will be used in further work on the factors involved in determining the in situ magnetization of upper layer 2 .

\section{Susceptibility, $k$, and the Ratio of Titanomagnetite Content to Grain Size}

No simple or common relationship is observed between these parameters which is consistent with the conclusions based on the linear relationship between $J_{s}$ and $k$. 


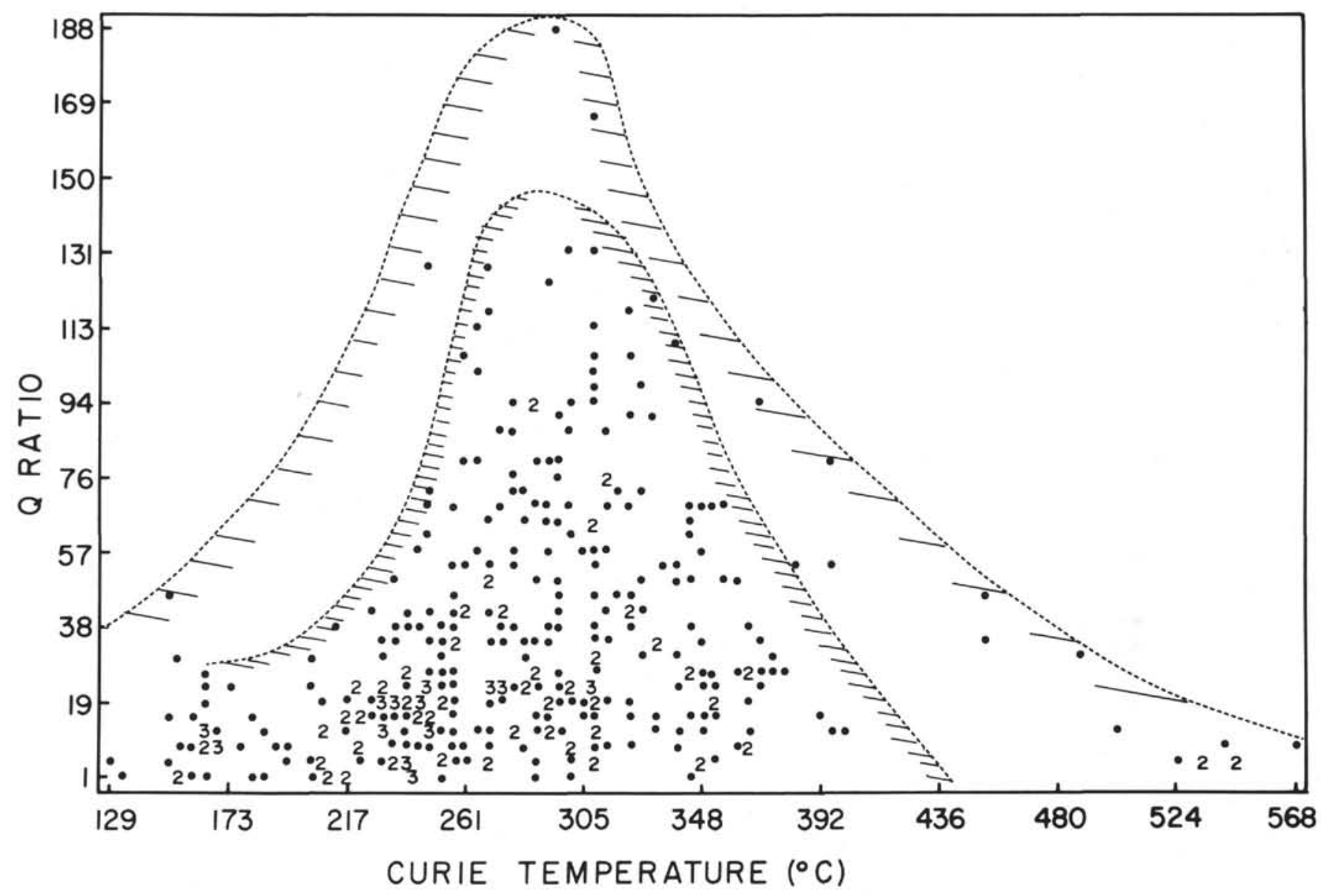

Figure 8. Relationship between Q ratio and Curie temperature for the Leg 37 basalts.

\section{MAGNETIC PROPERTIES OF BASALTS CONTAINING LOW CATION DEFICIENCY TITANOMAGNETITE}

Examination of Table 2 and the discussion of the scattergrams given clearly indicate that samples containing low cation deficiency titanomagnetite, for which $0.0<z<0.5$, have a distinctive set of magnetic properties. Thus, when compared with adjacent high cation deficiency samples, the low cation deficiency samples are characterized by relatively high NRM intensity, high susceptibility, high saturation magnetization, and low mean demagnetizing field. In these respects, we suggest, they most closely resemble, in terms of magnetic state, the original magnetic state of the Leg 37 basalts following eruption and cooling in the Median Valley of the Mid-Atlantic Ridge or elsewhere. By using the statistical analysis of rock magnetic properties of the Leg 37 basalts as a whole, it is instructive to estimate, for example, NRM intensity of the thick pillow sequences of Hole 332B and Sites 334 and 335 as they would have been after initial cooling. These estimates can then be compared with measured values for pillow lavas dredged from the Median Valley of the Mid-Atlantic Ridge in the project FAMOUS survey area. In this way the reality of the statistical trends can be tested. In making these estimates, we assume that the pillow basalts of the Median Valley contain stoichio- metric titanomagnetites, an assumption supported by the Curie points reported for such basalts (Johnson and Atwater, in press). If we correct the average NRM intensity of pillow sequences at Hole 332B and Sites 334 and 335 for the approximate decay in intensity in going from stoichiometric titanomagnetite to titanomagnetite with a relevant cation deficiency of $\sim 0.8$, we find that an increase of a factor of $\sim 7$ is indicated. Application of this factor suggests that average NRM intensities directly following initial cooling were in the 250 to $450 \times 10^{-4} \mathrm{emu} / \mathrm{cm}^{3}$ range. This range is somewhat in excess of values obtained for pillow lavas presently on the valley floor of $237 \pm 103 \times 10^{-4}$ (Johnson and Atwater, in press) and $145 \pm 25 \times 10^{-4}$ (Lecaille et al., 1974), but is interesting in that it indicates that highly magnetized basalts were present in the Median Valley in former times, and that the prominence of the central anomaly is a permanent feature of oceanic linear anomaly patterns.

\section{SUMMARY AND DISCUSSION}

The most interesting results of this investigation are (a) the dominance of fairly highly cation deficient titanomagnetite as the magnetic phase of the basalts, (b) the lack of a simple dependence of average basalt low temperature oxidation state on basalt age or subbasement depth, and (c) the differences in dependence 


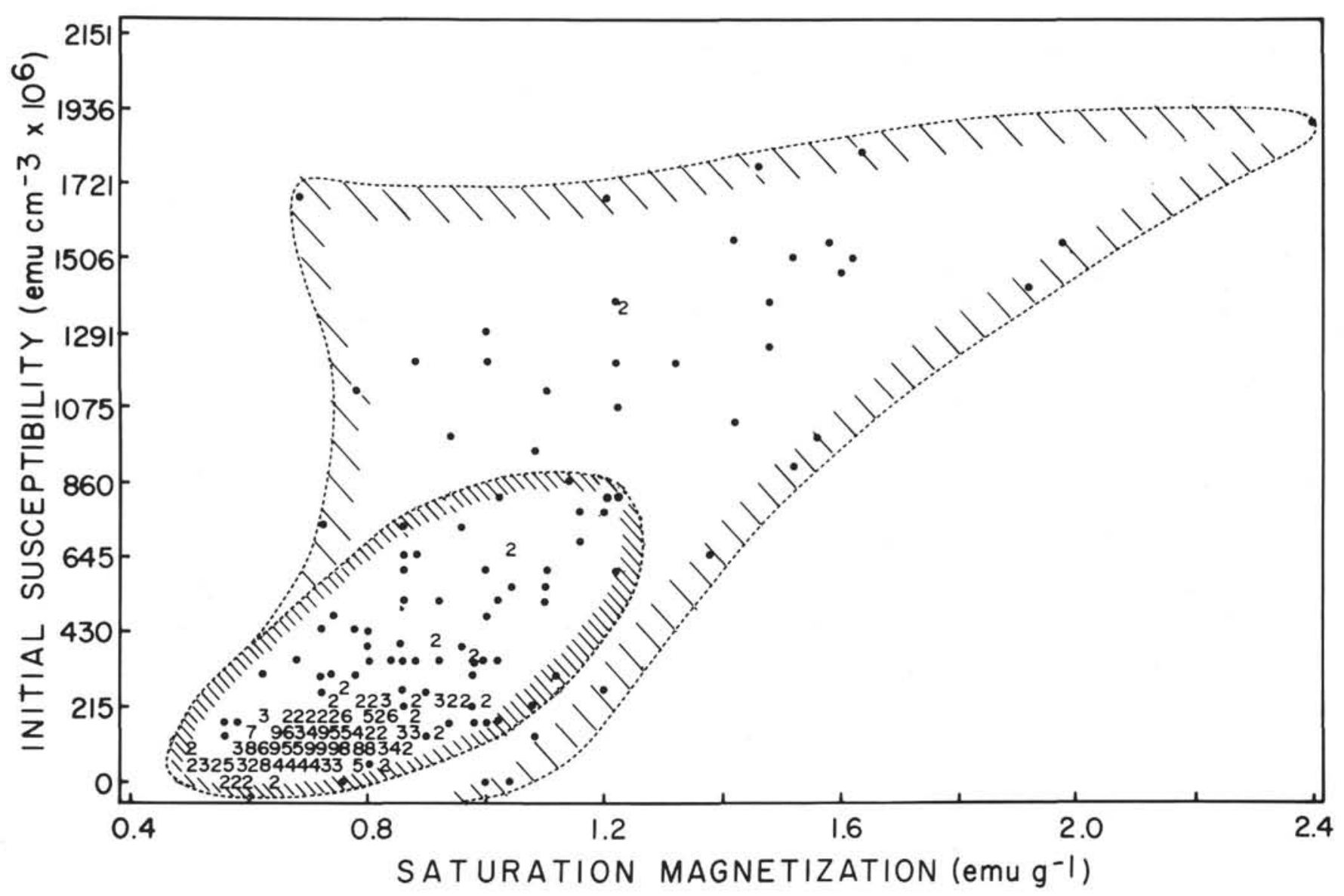

Figure 9. Relationship between initial susceptibility and saturation magnetization for the Leg 37 basalts.

of NRM intensity and susceptibility on degree of cation deficiency and other parameters, thus leading to a situation where the abundant fairly highly oxidized basalts are the best of possible materials for the production of clear linear magnetic anomaly patterns. Other results of significance are the evidence for basalt stoichiometric titanomagnetite composition being closely confined throughout and the evidence that the pillowed or massive nature of layer 2 basalts is a more important factor than age or subbasement depth in determining the progress of low temperature oxidation.

The almost complete absence of evidence, from both the magnetic and the ore-microscope work, for zeolite facies metamorphism in upper layer 2 is remarkable in view of estimates of temperature gradients in excess of $100^{\circ} \mathrm{C} / \mathrm{km}$ for layer 2 during its formation. This suggests that such high gradients, if they exist at all, are restricted to the vicinity of very localized upwellings of hydrothermal waters. In the median volcanic zone of Iceland, for example, these are widely scattered and are typically on the order of $1 \mathrm{~km}^{2}$ in area and are atypically large if in excess of $10 \mathrm{~km}^{2}$. If this is also the case in the Median Valley of the Mid-Atlantic Ridge then the probability of drilling into layer 2 rocks of any particular age that have acted as a passage for hydrothermal waters is low.

\section{ACKNOWLEDGMENTS}

We would like to acknowledge the able assistance of the shipboard scientific and technical staff on DSDP Leg 37 for much help in sampling for magnetic studies the basement rocks recovered. In the laboratory of Dalhousie University, Jeff Clark and Tim Milligan made most of the rock magnetic measurements, while Glen Johnson was responsible for all computing operations and Jan Aumento for drafting. Mary Ann Annand and Ruth Feldbauer typed the drafts of this manuscript and Paul Johnson provided a critical review. We are grateful to all these friends and colleagues.

\section{REFERENCES}

Ade-Hall, J.M., Fink, L.K., and Johnson, H.P., 1976a. Petrography of opaque minerals, Leg 34. In Hart, S.R. Yeats, R.S., et al., Initial Reports of the Deep Sea Drilling Project, Volume 34: Washington (U.S. Government Printing Office)

Ade-Hall, J.M., Johnson, H.P., and Ryall, P.J.C., 1976b. Rock Magnetism of basalts, Leg 34. In Hart, S.R., Yeats, R.S. , et al., Initial Reports of the Deep Sea Drilling Project, Volume 34: Washington (U.S. Government Printing Office), p. 459-468.

Gromme, S. and Mankinen, E.A., 1976. Natural remanent magnetization, magnetic properties, and oxidation of titanomagnetite in basaltic rocks from DSDP Leg 34. In Hart, S.R., Yeats, R.S., et al., Initial Reports of the Deep Sea Drilling Project, Volume 34: Washington (U.S. Government Printing Office), p. 485-494.

Irving, E., Park, J.K., Haggerty, S.E., Aumento, F., and Loncarevic, B.D., 1970. Magnetism and opaque mineralogy of basalts from the Mid-Atlantic Ridge at $45^{\circ} \mathrm{N}$. Nature, v. 228 , p. $974-976$.

Johnson, H.P. and Atwater, T., in press. A magnetic study of the basalts from the Mid-Atlantic Ridge at $37^{\circ} \mathrm{N}$. Geol. Soc. Am. Bull. 
Lecaille, A., Prevot, M., Tanguy, J.-C., and Francheteau, J., 1974. Intensite d'aimantation de basaltes dragues dans le rift medio-atlantique vers $36^{\circ} 50^{\prime}$ N: C.R. Acad. Sci. Paris, v. 279 , p. $617-620$.

O'Reilly, W. and Banerjee, S., 1966. Oxidation of titanomagnetite and self reversal: Nature, v. 221, p. 26-27.

Ozima, M. and Larson, E.E., 1968. Study of self-reversal of TRM in some submarine basalts: J. Geomag. Geoelect., v. 20 , p. $337-351$.

Ozima, M., Joshima, M., and Kinoshita, H., 1974. Magnetic properties of submarine basalts and the implications on the structure of the oceanic crust: J. Geomag. Geoelect., v. 26 , p. $335-354$.
Readman, P.W. and O'Reilly, W., 1970. The synthesis and inversion of non-stoichiometric titanomagnetites: Phys. Earth Planet Inter., v. 4, p. 121-128.

1972. Magnetic properties of oxidized (cationdeficient) titanomagnetites (Fe, Ti, $\square$ ) $\mathrm{O}_{+}$. J. Geomag. Geoelect., v. 24, p. 69-90.

Schaeffer, R.M. and Schwarz, E.J., 1970. The Mid-Atlantic Ridge near $45^{\circ} \mathrm{N}$ : Thermomagnetics of dredged samples of igneous rocks: Canadian J. Earth. Sci., v. 7, p. 268-273.

Seyfried, W.E., Shanks, W.C., and Bischoff, J.L., 1976. Alteration and vein formation in Site 321 basalts. In Hart, S.R. Yeats, R.S., et al., Initial Reports of the Deep Sea Drilling Project, Volume 34: Washington (U.S. Government Printing Office), p. 385:392. 